\title{
The Interactive Nature of Business Development Services in The Relationship Between External Business Environment and Firm Performance
}

\author{
Washington 0. Okeyo \\ P.0 Box 20530 - 00200, Nairobi Kenya
}

\begin{abstract}
This study focused on the interaction of business development services in the external business environment and firm performance relationship. The study adopted a cross sectional survey design on 800 small and medium manufacturing enterprises in Kenya. Data were collected using structured questionnaires from a sample of 150 enterprises and $64 \%$ responded. The instrument was tested for reliability using Cronbach's approach while data was tested for normality and homoscedasticity before applying regression methods to test hypotheses. Principal component analysis was used to determine suitable predictor variable factors for regressions. The study established that external business environment has a significant positive but partial effect on performance and that business development services partially mediate this relationship. The study recommends that small and medium enterprises should embrace business development services practices to leverage the effect of external business environment on their performance.
\end{abstract}

Key words: External, business, environment, services, mediation, small, medium, enterprises, performance

\section{Background}

\section{INTRODUCTION}

Research focusing on small and medium enterprises (SMEs) has gained tremendous momentum over the past several decades. Most of this research has been concerned with investigating SME performance (Williamson, 1985; Venkataram \& Ramanujan, 1986). According to Okeyo, Gathungu and K'Obonyo (2014:40), performance may be viewed as "the extent to which a firm competes, takes its products to the market, appeals to the community, attracts potential employees and makes profits for its stakeholders." Jensen and Meckling (1976) argue that the main objective of a commercial firm is to maximize shareholder wealth in order to increase its overall performance. Performance is thus a fundamental issue which all firms regard as an important measure of shareholder wealth.

However, studies have reported constrained performance among SMEs (Adeniran \& Johnson, 2011; Fatoki, 2012). The constrained performance has been attributed to lack of scale economies to acquire resources for SME activities. Penrose (1959) stated that organizations differ in performance based on resources possessed and how they use them. Rare, valuable, and inimitable resources give organizations competitive advantage (Barney, 1997; Cardeal \& Antonio, 2012). Therefore, SMEs need to embrace prudent business practices to maximize resource acquisition and use. A practice known as business development services (BDS) is said to exist among SMEs that embrace technology and product development, are located close to markets, have appropriate infrastructure facilities, and espouse proficient procurement services aimed at improved resource utilization. 
Business development services are viewed as a multiplicity of activities through which SME practitioners enhance management of their enterprises (McVay \& Miehlbradt, 2003). Price, Stoica and Boncella (2013) argue that BDS can enable SMEs identify and access appropriate markets for their goods. Quick market access makes SMEs reach their customers proactively leading to first-mover advantage, and superior customer relationship and retention (Lumpkin \& Dess, 1996). BDS also means having appropriate infrastructure facilities for warehousing and preservation of finished goods. White, O'Conor and Rowe (2004) suggest that SMEs may hire, or own warehouses to secure their products before channeling to destination markets.

Furthermore, through BDS SMEs can negotiate favourable procurement terms and conditions by making group purchase arrangements. Humphrey and Schmitz (1995) argue that the needs of firms organized into a group can more easily be felt in institutions and markets. For example service providers like suppliers, banks, training providers and other institutions may feel more comfortable responding to the requirements of a group rather than individual firms. Therefore, adopting BDS practices may provide SMEs with ability to possess valuable resources for their activities. Resource dependence theory reasons that organizations depend on the external environment for their resources (Pfeffer \& Salancik, 1978), thus conditions prevailing in the environment can dictate the quest of SMEs to access resources.

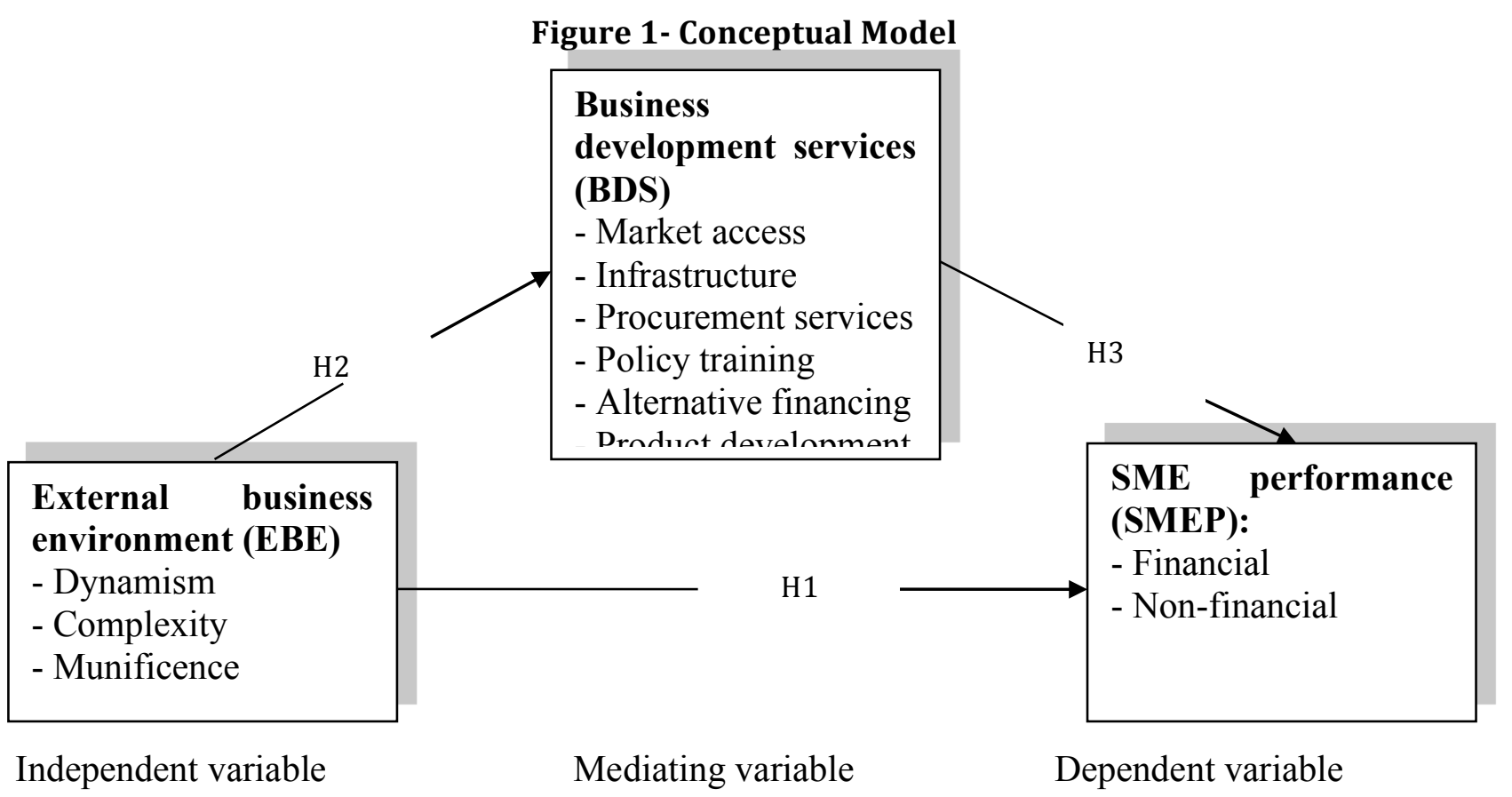

Figure 1 shows the linkages among variables and the hypotheses that guided the study

Johnson and Scholes (2002) suggest that external business environment may be viewed as a composite of political, economic, socio-cultural, technological, ecological, and legal/regulatory factors. Past studies for example Bluedorn et al (1994), and Bajari and Tadelis (2001) have analyzed how these factors affect firm performance. However opinions regarding this relationship are still divided (Shane \& Spicer, 1983; Chittithaworn, Islam, Keawchana \& Yusuf, 2010). Shane and Spencer (1983) found a negative effect while Chittithaworn et al (2010) reported a positive relationship. As such SMEs can tame the ubiquitous hostile environment by adopting business development services to improve their performance. Therefore this study investigates the interactive role of business development services in the link between external environment and performance of SMEs in Kenya as conceptualized in Figure 1. The study seeks 
Okeyo, W.O. (2015). The Interactive nature of Business Development Services in the relationship between external business environment and firm performance. Advances in Social Sciences Research Journal, 2(2) 164-177.

to answer question: Does external environment have any impact on performance of SMEs in Kenya and does business development services intervene in this relationship?

\section{Objectives}

The broad objective of this study was to establish the role of business development services in the relationship between external business environment and firm performance. Specific objectives were to:

I. Establish the effect of external business environment on performance of SMEs

II. Determine how business development services influences the effect of external business environment on performance of SMEs

\section{External business environment}

\section{LITERATURE REVIEW}

Osborne and Hunt (1974) describes business environment as the infinite set of factors in the periphery of a firm's borders; together with other organizations, broad forces and associations of individuals. According to Li (1998), all organizations depend on the environment as an important source of essential business resources and information. But SMEs face challenges such as lack of capacity and resources, and inadequate knowledge of environments. SMEs also experience constrained scale economies which limit their effectiveness. Thus external business environment is a critical and relevant issue for SME performance. Although the environment has been analyzed in past studies in several forms, the most common concerns in extant literature are its dynamism, complexity, and munificence. This is consistent with organizational literature (Dess \& Beard, 1984; Goll \& Rasheed, 2004) which indicates that dynamism, complexity, and munificence are the three critical states of external business environment for SME performance.

\section{Dynamism}

Goll and Rasheed (2004) argue that the extent of SME performance depends on how they manage environmental changes. Managing such changes depends on observing their dynamics, complexities and consequences; and establishing requisite strategies to obtain appropriate resources. Past research suggests that the vibrant nature of these environmental dimensions is a crucial factor in resource availability for SMEs and their performance. For example, dynamism, a key aspect of business environment has been observed to be of significant consequence to SME performance (Gilley \& Rasheed, 2000). Research also indicates that SMEs operating in dynamic environments require more resources to plan and manage changes pertaining to political, economic, socio-cultural, technological, environmental, and legal cum regulatory activities (Okeyo, 2014; Machuki \& Aosa, 2011).

Aluko (2003) found that changes in political landscape and socio-cultural dynamics, among other factors, play a key role in the formation, management, and growth of SMEs in Nigeria. On a similar note, economic analysis reports on Kenya indicate that politically influenced policies and resource allocations have led to serious marginalization of counties located in north eastern, western, and northern regions of the country (Fitzgibbon, 2012) while cultural influences have been observed to spur entrepreneurial startups only in some communities. Furthermore, empirical analyses show that fluctuations in economic factors such as interest rates, inflation, exchange rates, and foreign currency shortage have resource implications for SMEs in Zimbabwe. In another study, Matambalya and Wolf (2001) state that increased adoption of technologies such as mobile phones, internet and computers is a major factor for improved firm performance. These studies suggest that environmental dynamism in a crucial issue that gobbles up much of SME resources. 


\section{Complexity}

Studies also indicate that environmental complexity may force organizations to deploy more resources towards dealing with the situation. Empirical literature suggests that environmental business complexity may be viewed in terms of large numbers of business related issues that firms have to address. In other words, it is the large array of factors in the environment that makes it complex. As such, differences and dissimilarities in these issues pose a serious challenge to many SMEs. Johnson and Scholes (2002) argue that arising from political dimension of the environment, SMEs need to deal with the government's (in)stability, taxation policy, foreign trade regulations and social welfare policies whereas economically, firms are faced with business cycles, gross national product (GNP) trends, interest rates, inflation, unemployment, and disposable income constraints.

The scholars further point out that important socio-cultural factors which are also crucial to SME businesses are demographic changes, social mobility, lifestyle changes, consumerism, and levels of education while technology issues relate to government spending on research, focus on technology, new discoveries/development, technology transfer and rates of obsolescence. Also of interest to SMEs are laws protecting the environment, waste disposal, and energy consumption and finally, legal issues which encompass legislations on monopoly, employment, health and safety, and product safety (Johnson \& Scholes, 2002). Thus, complexity represents an important environmental condition for SMEs.

\section{Munificence}

The last environment state of significant importance to SMEs is munificence. Munificence is regarded as the tendency towards abundance or availability of resources in the business environment (Goll \& Rasheed, 2004). In an empirical study, Patel and D'Souza (2009) infer that, as opposed to larger firms, "liability of smallness" in SMEs can constrain their initiatives to acquire resources in the environment. In particular, SMEs in the manufacturing sector often require a substantial amount of resources to fund their operations yet returns from such investments are usually not expected until way into the future (Busienei, K'Obonyo \& Ogutu, 2013). Moreover, conditions in the environment often undergo rapid changes making the once favourable resource sources uncertain. Furthermore, because SMEs are often constrained of knowledge of their environment and linkages with suppliers and customers their ability is limited. Thus SMEs are in a disadvantaged position in the marketplace.

In such a vulnerable position, a key challenge is to manage the obstacles impeding SME efforts to access necessary resources for their activities. Literature suggests that environmental munificence is of serious importance to SME survival and growth (Goll \& Rasheed, 2004). But this important phenomenon seems to have attracted relatively little attention (Gilley \& Rasheed, 2000). It is in this light that this study used perceptual measures of munificence to examine how the environmental condition affects SME performance. Perceptual approaches to environment find support in "enactment theory" which posits that, through decision making in organizations, environmental situations may be perceived or experienced (Weick, 1969). Arising from the foregoing reviews and views, it is evident that changes in external business environment affect SMEs and may impact on their performance. Therefore, this study predicts that -

H1: External business environment has a positive impact on SME performance 


\section{Business development services}

Business development services are concerned with provision of development services to improve performance of small businesses. Development services are used to identify and analyse opportunities for an enterprise and supporting them through implementation. Miehlbradt and McVay (2003) defined business development services as an array of activities that SMEs use in managing their operations to enhance their efficiency, effectiveness and improve their performance and competitiveness. UNCTAD (2005) has described BDS as the SME support services related to training, infrastructure, consulting, technical, and management as well as advocacy and policy development.

The need for SMEs to improve their performance, create wealth for their owners, and contribute to economic development has been given prominence in literature. For example Atieno (2012) examined factors related to linkages and performance of SMEs in Kenya and established that inadequate capacity hinders SMEs from bidding for business contracts. Brijlal (2008) point out that SME performance can be improved by enhancing demand and supply side factors around their operations and specifically identifies "skills, networks, access to resources, infrastructure, and availability of information and government regulations and policies (p 49)" as the main constraints facing SMEs. Also Okeyo (2014) citing Moorthy et al (2012) argued that organizations having close proximity to markets may experience superior performance through easy market access. Therefore, SMEs that embrace BDS practices through adequate infrastructure facilities, product development, prudent procurement services, easy market access, and suitable policies may have competitive advantage.

\section{External business environment, business development services, and SME performance}

Performance of SMEs has been a major area of concern to entrepreneurs, business practitioners, managers, and policy makers. Equally, it has been of great interest in academic research the world over (Li, 2001; Sum, Jukow, \& Chen, 2004; Nyangori, 2010 Bhamani, Kaim \& Khan, 2013). This demonstrates that SMEs are viewed as important organizations in many economies. Literature (Okeyo, 2014:60) argues that "SMEs have for a long time been regarded as engines of growth in many countries." Atieno (2012) attributes the growth of the Kenyan economy partly to SMEs through employment and income generation, especially among youth and women. This view was supported in the 1999 national economic survey which reported that the total number of households involved in diverse small businesses in Kenya stood at $26 \%$.

However, despite this impressive role and contribution to employment, income generation, and economic growth, SMEs experience very high failure rates (Adeniran \& Johnson, 2011; Nyangori, 2010). Sources and cost of finance, uncontrollable conditions in the business environment and inadequate internal capacities are some factors that have been blamed for SME underperformance and failures (Suh, 2010; Yusuf \& Dansu, 2013). It has also been argued that SMEs that embrace business development practices may experience improved performance. Brijlal (2008) reports that proactive SMEs having quick access to markets can overcome market failures, and enjoy first-mover advantage when delivering their innovative products to markets. Therefore the interplay between business environment and business development services is a critical issue for SME performance. But it is not clear from past studies how business environment and business development services interact in a contingency framework to affect performance. 


\section{Mediating role of business development services}

The effect of business development services on firm performance has mainly been studied as a direct relationship. Mehta et al (2007) however point out that although a strong direct relationship exists, the impact is not always conclusive. Therefore, business development services may interact with other business phenomena to impact firm performance. Baron and Kenny (1986) argue that apart from primary functions, variables may play a third interactive role in an inter-variable relationship. They specifically point out that where this relationship is inconclusive, other mediating or moderating variables may be involved. However, extant literature shows that there is a dearth of studies investigating the mediating role of business development services on performance. Shehu et al (2014) paid attention only to selected aspects of BDS and found that the aspect of advisory services partially mediates the link between owner/manager complexity and marketing decision. Therefore, to examine the interactive role of BDS in the external business environment and performance relationship, it was hypothesized that:

H2: External business environment positively impacts on business development services

H3: Business development services partially mediates the relationship between external business environment and SME performance

\section{Study design and data collection}

\section{METHODOLOGY}

This was a cross sectional study and it targeted over 800 small and medium enterprises in the manufacturing sector operating in Nairobi County who were members of Kenya Manufacturing Association as at the end of 2012. This smaller and younger population formed an ideal context to study interactive nature of business development services. Also focusing on one sector, manufacturing reduces heterogeneity in other variables likely to affect performance variance (Wales, Patel, \& Lumpkin, 2013). This focus further acts as a mitigating mechanism for other industry based factors likely to have an effect on performance. Data was collected from a representative sample of 150 enterprises which were chosen using stratified random and sequential sampling techniques. Structured questionnaires which were administered through drop and pick methods were used to collect primary data from the SME senior managers or owners.

\section{Measurement of variables and data analysis}

At the end of data collection, 95 questionnaires were returned giving a response rate of $64 \%$. Before this however, the instrument was pilot tested on ten enterprises with similar characteristics as the population but not part of the final sample. The questionnaire was designed in a five point Likert type scale format and had three sections for external business environment, business development services, and SME performance respectively. External business environment was measured using a total of 18 questions of which six focused on complexity and asked "how frequently your organization has to deal with issues related" to politics, economy, social/culture, technology, ecology and regulations.

Dynamism was determined by asking the extent to which the SME was able to predict the same issues while for munificence, the organizations were asked to rate how developments in the same environmental issues favoured them. Business development services was likewise determined based on a five point Likert type scale but using a total of ten questions two on; market access, procurement, financing, technology and product development, policy, and infrastructure respectively. Finally, SME performance was measured based on financial 
indicators comprising percentage growth in; profits, sales, and return on assets, and nonfinancials consisting of improvement in customer, and employee satisfaction respectively.

In order to arrive at the final value for external business environment, factor analysis was used to determine a suitable factor combination from the original 18 questions. The analysis identified ten factors, shown in Table 1, whose aggregate was calculated and used as a measure of external business environment.

Table 1: Principal component analysis for external business environment

\begin{tabular}{lr}
\hline Factors & Component 1 - values \\
\hline Regulatory complexity & 0.506 \\
Ecological complexity & 0.605 \\
Economic dynamism & 0.500 \\
Technological dynamism & 0.630 \\
Socio-cultural dynamism & 0.563 \\
Regulatory dynamism & 0.580 \\
Ecological dynamism & 0.705 \\
Economic munificence & 0.503 \\
Technological munificence & 0.535 \\
Ecological munificence & 0.607 \\
\hline
\end{tabular}

Similarly, during factor analysis for BDS, the dimensions were reduced by half to five factors, as shown in Table 2, which were then totaled to give the final value for BDS. Lastly the value for performance was determined by adding up the responses from all the questions.

Table 2: Principal component analysis for business development services

\begin{tabular}{lr}
\hline Factors & Component 1 - values \\
\hline Access to advertising facilities & 0.620 \\
Linkage to technology suppliers & 0.591 \\
Access to product design services & 0.756 \\
Group purchasing arrangements & 0.694 \\
Storage/warehousing facilities & 0.677 \\
Training on policy skills & 0.603 \\
\hline
\end{tabular}

\section{RESULTS}

Results for this study are based on data received from 95 out of a sample of 150 respondents giving a response rate of $64 \%$. Analysis of the respondent characteristics shows that most of the organizations which answered had 200 or fewer employees while the oldest enterprise had been in business for 20 years. The analysis further indicates that sub-sectoral response was proportional to the respective samples. These characteristics show a balanced representation of the entire manufacturing sector in the analysis and confirm that this was a youthful population of SMEs in which BDS practice could manifest hence suitable for studying the phenomenon.

\section{Tests for reliability, homoscedasticity and normality}

Data for the study were tested for reliability, normality, and homoscedasticity respectively to verify their suitability for further analysis. Homoscedasticity tests on performance using 
$\mathrm{Z}^{*}$ pred were normal while Cronbach's alpha values for the results of reliability tests are presented in Table 3.

Table 3: Summary of Cronbach's alpha test results

\begin{tabular}{lrrr} 
Variable & $\begin{array}{r}\text { Cronbach's } \\
\text { Alpha }\end{array}$ & $\begin{array}{r}\text { Cronbach's } \\
\text { Alpha } \\
\text { (Standardized) }\end{array}$ & $\begin{array}{r}\text { Number of } \\
\text { Items }\end{array}$ \\
\hline External business environment (EBE) & 0.813 & 0.813 & 10 \\
Business development services (BDS) & 0.761 & 0.764 & 6 \\
SME performance (SMEP) & 0.868 & 0.874 & 6 \\
\cline { 2 - 3 }
\end{tabular}

As shown in Table 3, Cronbach's alpha values are $0.813,0.764$, and 0.874 for EBE, BDS, and SMEP respectively. According to Nunnally (1967), an alpha value of 0.70 or more is considered a good indicator of instrument reliability. Since the scale values from the tests are all above 0.70 , this confirms that the instrument used was reliable across different respondents and hence the data accurately depicts consistent respondents' views regarding the three factors in all the organizations under study.

\section{Descriptive statistics}

Data were analyzed to determine their means and standard deviations. The aim was to establish the perception of respondents regarding importance and disparity in their opinions about the study variables. The values for the means and standard deviations are presented in Table 4.

Table 4: Descriptive statistics

\begin{tabular}{|c|c|c|c|c|}
\hline Variables & Minimum & Maximum & Mean $(\mu)$ & $\begin{array}{l}\text { Standard } \\
\text { Deviation }(\sigma)\end{array}$ \\
\hline $\begin{array}{l}\text { External business } \\
\text { environment (EBE) }\end{array}$ & 18.00 & 46.00 & 36.20 & 5.73 \\
\hline $\begin{array}{l}\text { Business development } \\
\text { services (BDS) }\end{array}$ & 11.00 & 31.00 & 21.63 & 4.71 \\
\hline $\begin{array}{l}\text { SME } \\
\text { (SMEP) }\end{array}$ & 6 & 26 & 16.09 & 5.18 \\
\hline
\end{tabular}

According to the results in Table 4, EBE had lowest and highest values of 18.00 and 46.00 respectively and a mean score of 36.20 . The mean value is skewed towards the maximum score of 46.00 indicating that most respondents preferred high scores for EBE thus perceiving the variable to be important in their businesses. Similarly, the table indicates that BDS values range from 11.00 to 31.00 with a mean score of 21.63 indicating that businesses perceived BDS to also be important. Finally, the respondents were somewhat indifferent about the importance of SMEP since the mean value of 16.09 is the same as the median. The standard deviation was however higher for $\operatorname{EBE}(\sigma=5.73)$ than $\operatorname{BDS}(\sigma=4.71)$ indicating greater variation in respondents' opinions regarding EBE compared to BDS and performance respectively.

\section{Tests of study hypotheses}

The main approach used for analysis in this study was linear regressions on the Statistical Package for Social Sciences (SPSS) software. They were used to test all the study hypotheses at significant levels of $1 \%, 5 \%$ and $10 \%$ or $p \leq 0.001, p \leq 0.05$, and $p \leq 0.10$ respectively. Hypothesis $\mathrm{H} 1$ which stated that "external business environment has a significant positive effect on SME performance" was tested using model 1 : SMEP $=\beta 0+\beta 1 \mathrm{EBE}+\dot{\varepsilon}$ while hypothesis H2 which 
predicted that, BDS mediated the effect of EBE on SME performance, was tested by combination of models $2: \mathrm{BDS}=\beta 0+\beta 1 \mathrm{EBE}+\dot{\varepsilon}^{\prime}$ and model 3 : SMEP $=\beta 0+\beta 1 \mathrm{BDS}+\beta 1 \mathrm{EBE}+\dot{\varepsilon}^{\prime}$. The regression results for the three models may be expressed in the following three equations.

0.064 SMEP $=7.780+0.231$ EBE; $\mathrm{p} \leq 0.02$

$0.117 \mathrm{BDS}=11.487+0.279 \mathrm{EBE} ; \mathrm{p} \leq 0.002$

0.176 SMEP $=2.885+0.132$ EBE + 0.385 BDS; $\mathrm{p} \leq 0.001$

The results of these tests are summarized in Table 5 .

Table 5: Tests of study hypotheses

\begin{tabular}{|c|c|c|c|}
\hline Variables $\Rightarrow$ & EBE & BDS & ANOVA \\
\hline \multicolumn{4}{|l|}{ Models I } \\
\hline \multicolumn{4}{|l|}{ Model 1: } \\
\hline$\beta$ & 0.231 & - & \\
\hline $\mathrm{R}^{2}$ & 0.064 & - & \\
\hline $\mathrm{p}$ & $\mathrm{p} \leq 0.02$ & - & \\
\hline $\mathrm{F}$ & $5.627 * *$ & & \\
\hline \multicolumn{4}{|l|}{ Model 2: } \\
\hline$\beta$ & 0.279 & - & \\
\hline $\mathrm{R}^{2}$ & 0.117 & - & \\
\hline $\mathrm{p}$ & $\mathrm{p} \leq 0.002$ & - & \\
\hline $\mathrm{F}$ & $10.331 * * *$ & & \\
\hline \multicolumn{4}{|l|}{ Model 3: } \\
\hline$\beta$ & 0.132 & 0.383 & \\
\hline $\mathrm{R}^{2}$ & 0.176 & 0.176 & 0.176 \\
\hline $\mathrm{p}$ & $\mathrm{p}>1.0$ & $\mathrm{p} \leq 0.003$ & $\mathrm{p} \leq 0.001$ \\
\hline $\mathrm{F}$ & & & $7.919 * * *$ \\
\hline
\end{tabular}

The results from statistical tests for all hypotheses are shown in mathematical form in equations 1, 2, and 3, and summarized in models 1, 2, and 3 in Table 5 . The modeling of the equations to test for mediating effect of business development services in the relationship between external business environment and performance was carried out in accordance with Baron and Kenny (1986). First, a direct effect of external business environment on performance was evaluated. Model 1 shows the results for regressing SME performance on external business environment. The second test involved determining the relationship between external business environment and business development services and results shown in Model 2. The third and last test entailed testing the simultaneous effect of external business environment and business development services on performance which gave the results in model 3.

According to the results, $\mathrm{R}^{2}$ for model 1 is 0.064 . The model also shows a statistically significant effect $(\mathrm{p} \leq 0.02)$ and that the regression coefficient of the independent variable external business environment, is positive $(\beta=0.231)$. This indicates that the model may be used to explain variations in performance such that a unit change in external business environment causes a corresponding 6.4\% variation in SME performance. Although positive and statistically significant, this effect is however weak $(F=5.627)$. Model 2 which tested the 
effect of external business environment on business development services shows a positive regression coefficient $(\beta=0.279)$ and an $R^{2}$ for the model of 0.117 . These results show that changes in external business environment affects business development services favourably. Specifically, a unit change in the environment makes the elements of business development services fluctuate significantly to the level of $11.7 \%$. These variations in performance were major $(\mathrm{F}=10.331)$ and statistically significant $(\mathrm{p} \leq 0.002)$.

Lastly, model 3 presents the results showing how the interaction between external business environment and business development services affect performance. According to the results, business development services have a relatively large, positive and statistically significant effect on performance $(\beta=0.383, p \leq 0.003)$. However, external business environment depicts a relatively small but positive effect on performance $(\beta=0.132)$. This effect is though not statistically significant $(p>0.10)$. The model nevertheless shows that the contribution of external business environment on performance variation is relatively strong and statistically significant $(\mathrm{p} \leq 0.001)$. From this model 3 , the simultaneous variations as a result of external business environment and business development services account for $17.6 \%$ of the changes in performance $\left(\mathrm{R}^{2}=0.176\right)$. This effect is relatively strong $(\mathrm{F}=7.919)$ compared to external business environment alone ( $\mathrm{F}=5.627)$.

These results demonstrate that changes in external business environment cause a positive and significant variation on performance. This supports hypothesis H1 which predicted that "external business environment has a positive impact on SME performance." The results further show that external business environment has a positive influence on the proposed mediator, business development services. This indicates that the independent variable external business environment, affects the proposed mediator - business development services showing the possibility of business development services being a partial mediator for external business environment and thus showing support for hypothesis H2. Lastly, the effect of external business environment on performance $(\beta=0.132)$ in the simultaneous case (model 3 ) is less than its effect on performance $(\beta=0.231)$ in model 1 . This suggests that the introduction of business development services lowers the effect of external business environment on performance which confirms that business development services mediates the relationship between external business environment and performance thus supporting hypothesis H3.

\section{DISCUSSION}

Broadly, this study aimed to determine the function that business development services play as firms interact with the external business environment. Three hypotheses were tested to interrogate this thought. The results show that external business environment had a positive and significant effect on performance. This finding is consistent with extant literature (Porter, 1980; Kibera, 1996) which demonstrates that firms operating in dynamic and hostile environments report superior performance. According to Johnson and Scholes (2002), factors in the external business environment like economy, government regulations, environment, technology, and social/culture determine the level and type of resources that SMEs need to manage their dynamism, complexity, and munificence. The findings support hypothesis H1 which stated that "external business environment has a positive impact on SME performance." This study thus establishes that changes in the external business environment are likely to have a positive impact on SME performance.

The study also aimed to establish the interactive role of business development services in the external business environment and performance relationship. This was tested in hypotheses $\mathrm{H} 2$ and H3. The tests show that external business environment has a positive and significant 
effect on performance. According to Baron and Kenny (1986) and later Wales, Patel and Lumpkin (2013), a variable can only play a mediating role if its effect dependents on the independent variable. Tests for this relationship show that external business environment has a positive and significant effect on business development services. This confirms the view that business development services may be a mediator in this relationship and supports hypothesis $\mathrm{H} 2$.

However, according to the conditions documented in literature for detecting mediation effects, the introduction of a proposed mediator in the independent and dependent variable relationship should have the effect of reducing the impact of independent variable on the link. This condition was tested in hypothesis H3. The results show that when the proposed mediator - business development services, is introduced in the equation, the effect of external business environment becomes not statistically significant $(p>0.10)$ while the effect of business development services is positive and statistically significant $(\beta=0.383, p \leq 0.003)$. The test therefore supports the view that business development services mediate the effect of external business environment on performance. This finding is consistent with existing studies (Thompson, 1967; Williamson, 1979) which show that although external business environment has an impact on performance, this impact is only partial. It is also consistent with literature (Johnson \& Schools, 2002) which suggests that there could be other factors that dictate how firms react to changes in the external environment. This view is supported by Goll and Rasheed (2004) who found that external environment plays an indirect role on performance of organizations.

\section{LIMITATIONS, CONCLUSION, AND RECOMMENDATIONS}

This study experienced some limitations in spite of the reported results. Firstly, performance, the dependent variable was measured using perceptual indicators ostensibly because SMEs are averse to giving information showing their performance. Even if they do, SMEs consider this data confidential and hence do not give it out easily. Secondly, this was a cross sectional study which may involve comparing out of phase data - for example previous years' performance against current business development service practices and environmental conditions. Furthermore the population was narrowed to manufacturing enterprises yet SMEs in other sectors are also likely to embrace business development services. Future studies may therefore improve on these results by adopting other performance measures and focusing on populations in other sectors of the economy.

Despite these limitations, the study achieved its objectives and concludes that external business environment has a positive influence on performance such that changes in external environment are associated with better SME performance. The study also established that these effects are only partial indicating that other factors may play a role. More importantly, the study established that business development services are related to external environment such that environmental changes affect business development services in organizations. According to the study, this interaction between business environmental factors and development services causes a positive impact in performance of firms. This study therefore concludes that although external business environment has a positive effect on performance of small and medium manufacturing enterprises, this effect is only partial. Thus, it is established that business development services mediates this relationship resulting in improved performance of the enterprises. 
Arising from this conclusion, the study recommends that SMEs should embrace business development practices to achieve improved performance given the dynamic, complex, and munificent environments in which they operate. Specifically, establishing operations within close proximity to markets to facilitate quick access and capitalize on first-mover advantage should be a priority to these SMEs. Moreover, SMEs may benefit by adopting prudent procurement practices such as group purchasing arrangements which can lead to discounted prices.

\section{REFERENCES}

Aluko, m.a.o. (2003). The impact of culture on organizational performance in selected textile firms in nigeria. Nordic journal of african studies, 12 (2): 164-179.

Atieno, r. (2012). Gender, institutions, access to finance and development of small and medium enterprises in kenya. A draft paper submitted to the 2012 csae conference on economic development, oxford, march 18-20.

Adeniran t. V., \& johnston, k.a. (2011). Investigating the levels of internet capabilities in south frican small and medium enterprises in changing environments. 13th annual conference on www applications. Johannesburg 1416 september 2011-isbn 978-0-620-519182

Bajari, p., \& tidelis, s. (2001). Incentives vs transaction costs: a theory of procurement contracts. Rand journal ofeconomics, vol. 32(3) 387-407.

Barney jb (1997). Gaining and sustaining competitive advantage. Addison-wesley: reading, ma.

Baron, m. R. \& kenny, d. A. (1986). The moderator-mediator variable distinction in social psychological research: conceptual, strategic, and statistical considerations. Journal of personality and social psychology, vol. 51(6) 11731182.

Bhamani, m. A., kaim, m.s., \& khan, m. M. (2013). Depression in the elderly in karachi, pakistan: a cross sectional study. Bmc pyschiatry. Vol. 13181.

Bluedorn, a.c., johnson, r.a., cartwright, d.k., \& barringer, b.r. (1994). The interface of convergence of strategic management and organizational environment domains. Journal of management. Vol 20 (2) pp 201-262

Brijlal, p. (2008). Business development service: addressing the gap in the western cape, south africa. International business and economics research journal, 7(9), 49-56.

Buseinei, j., k'obonyo, p., \& ogutu, m. (2013). The effect of human resource strategic orientation on performance of large private manufacturing firms in kenya. Prime journals of business administration. Vol. 3(1)834-857.

Cardeal, n., \& antonio, n. (2012). Valuable, rare, inimitable resources and organization resources (vrio) or valuable, rare, inimitable resources capabilities (vri): what leads to competitive advantage? African journal of business management 6(37) 10159-10170.

Chittithaworn, c., islam, a., keawchana, t., \& yusuf, d.h. (2010). Factors affecting business success of small and medium enterprises in thailand. Journal of asian social science, vol. 7 (5) 180-190.

Dess, g. G., \& d. W. Beard: 1984, 'dimensions of organizational task environments', administrative science quarterly $29,52-73$.

Eisenhardt, k. M., \& schoonhoven, c. B. (1996). Resource-based view of strategic alliance formation: strategic and social effects in entrepreneurial firms. Organization science, 7

(2), 136-150.

Fatoki, o. (2012). Entrepreneurial orientation, debt finance and performance of small and medium enterprises in south africa. Journal of social science. 32(2) 121-131.

Fitzgibbon, c. (2012). Economics of resilience study - kenya country report. [online] available: https://www.gov.uk/government/uploads/system/uploads/attachment_data/file/

228500/teerr_kenya_background_report.pdf (december 11,2014)

Gilley, k. M. \& a. Rasheed: 2000, 'making more by doing less: an analysis of outsourcing and its effect on firm performance', journal of management 26, 763-790.

Goll, i., \& rasheed, a. A. (2004). The moderating effect of business environmental munificence and dynamism on the relationship between discretionary social responsibility and firm performance. Journal of business ethics. 49: 41- 54. 
Okeyo, W.O. (2015). The Interactive nature of Business Development Services in the relationship between external business environment and firm performance. Advances in Social Sciences Research Journal, 2(2) 164-177.

Humphrey, j., \& schmitz h. (1995). Principles for promoting clusters and networks of smes. Insitutte of development studies, university of sussex, u.k.

Jensen, m. \& meckling, w. (1976). The theory of the firm: managerial behaviour, agency costs, and ownership structure. Journal of economics. Vol. 3: 305-360.

Johnson, g., \& scholes, k. (2002). Exploring corporate strategy - sixth edition. New delhi: prentice hall of india private ltd.

Kibera, f. (1996). Introduction to business: a kenyan perspective. Kenya literature bureau, nairobi.

Li, h. (2001). How does new venture strategy matter in the environment - performance relationship? Journal of high technology management research. Vol. 12 (2001) 183204.

Li, h. (1998). Marketing strategies and new venture performance in china's transitional economy. Ann arbor, mi: university microfilms, no. 9908697.

Lumpkin, g.t., \& dess, g.g. (1996). Clarifying the entrepreneurial orientation construct and linking it to performance. Academy of management review. 21, 135-172.

Machuki, v.n. \& aosa, e. (2011). The influence of the external business environment on the performance of publicly quoted companies in kenya. Prime journals, 7, pp 205-218.

Matambalya, f. \& wolf, s. (2001). The role of icts for the performance of smes in east africa. Zef-discussion papers on development policy, bonn, december 2001

Mehta, m., virjee, k., evans, b. \& wathobio, k. (2007). Business development services for community managed small water enterprises. Water sanitation program: nairobi kenya.

Mcvay, m. \& miehlbradt a.o. (2002). 'background reader, business development services', 3rd annual bds seminar, turin, italy, 9-13 september 2002.

Moorthy, k., tan, a., choo c., wei, c.s., ping, j.t.y., \& leong, k.t. (2012). A study of factors affecting the performance of smes in malaysia. International journal of academic research in business and social sciences, vol. 2 (4) pp 224-238 issn: $2222-6990$

Nyangori, r. (2010). Factors influencing performance of micro and small enterprises: a case of kisumu city bus park-kenya. Retrieved from www.academia.edu on 27 june 2014.

Nunnally, p. (1967). Psychometric theory. 1st edition new york: mcgraw hill

Okeyo, w.o. (2014). The influence of business environmental dynamism, complexity and munificence on performance of small and medium enterprises in kenya. International journal of business and social research. Vol. 4(8) 59-73

Okeyo, w.o., gathungu, j.m.s., \& k'obonyo, p. (2014). The impact of business development services on entrepreneurial orientation and performance of small and medium enterprises in kenya. International journal of business and social research. Vol. 4 (7):38-49

Osborn, n. R. \& hunt, g. J. (1974). "environment and organizational effectiveness" administrative science quarterly, 19 (2): 231-246.

Patel, p.c \& d'souza, r. R (2009). Leveraging entrepreneurial orientation to enhance sme export performance. An office of advocacy working paper, small business association, sbahq-08-m-0320.

Penrose, e. T. (1959). The theory of the growth of the firm. New york: john wiley.

Pfeffer, j. \& salancik, g. R. (1978). The external control of organizations. New york: happeand row.

Porter, m. (1980). Competitive strategy. New york: ny, free press.

Price, d.p, stoica, m, \& boncella, rj (2013). The relationship between innovation, knowledge and performance in family and non-family firms: an analysis of smes. Journal of innovation and entrepreneurship, vol. 2 (14) 1-20

Shane, p. B. \& spicer b. H. (1983). 'market response to environmental information produced outside the firm', accounting review 58 (3), 521-536.23.

Shehu, a.m., aminu, i.m., mat, nkn, nasiru, a., johnson, pom., tsagm, m.m., and kura, k.m. (2013). The mediating effect between some determinants of sme performance in nigeria. Scientific and academic publishing. Vol. 3 (4) 237-242. 
Suh, j.d. (2010). Risks and opportunities facing smes in the post-crisis era. Poster presented at the apec smes training workshop, taipei, korea may 24 th - 28th, may.

Sum, c., jukow, l., \& chen, s. (2004).taxonomy of operations strategies of high performing small and medium enterprises in singapore. International journal of operations and production management, 24(3), 321-345.

Thompson, j.d. (1967). Organizations in action. New york: mcgraw-hill.

Unctad (2005). United nations conference on trade and development. Improving the competitiveness of smes through enhancing productive capacity. World investment reports - proceedings of four expert meetings, new york and geneva.

Venkatraman, n. \& ramanujam, v. (1986). "measurement of business performance in strategy research: a comparison of approaches". Academy of management review. 1(4): 801-814.

Wales, w. J., patel, p.c., \& lumpkin, g.t. (2013). In pursuit of greatness: ceo narcissism, entrepreneurial orientation, and firm performance variance. Doi 10.1111/joms.12034

Weick, k. E. (1969). The social psychology of organizing. Reading, ma: addison-wesley.

White, w. J., o'connor, a.c., \& rowe, b.r (2004). Economic impact of inadequate infrastructure for supply chain integration. Paper prepared for national institute of standards and technology, research triangle park, north carolina.

Williamson, o. E. (1979). Transaction costs economics: the governance of contractual relations. Journal of law and economics .vol. 22(2) pp. 233-261.

Yusuf, t.o., \& dansu, f. S. (2013). Smes, business risks and sustainability in nigeria. European journal of business and social sciences, vol. 2 (9) pp76-94. 